\title{
Effect of treating periodontitis on C-reactive protein levels: a pilot
} study

\author{
Kimmo Mattila*1, Marja Vesanen ${ }^{2}$, Ville Valtonen ${ }^{1}$, Markku Nieminen 1 , \\ Timo Palosuo ${ }^{3}$, Vesa Rasi ${ }^{4}$ and Sirkka Asikainen ${ }^{2}$
}

Address: ${ }^{1}$ Department of Medicine, Divisions of Infectious Diseases and Cardiology, Helsinki University Central Hospital, Helsinki, Finland, ${ }^{2}$ Institute of Dentistry, University of Helsinki, Finland, ${ }^{3}$ National Public Health Institute, Helsinki, Finland and ${ }^{4}$ Finnish Red Cross Blood Transfusion service, Helsinki, Finland

E-mail: Kimmo Mattila* - kimmo.mattila@hus.fi; Marja Vesanen - sirkka.asikainen@odont.umu.se; Ville Valtonen - ville.valtonen@hus.fi; Markku Nieminen - markku.nieminen@hus.fi; Timo Palosuo - timo.palosuo@ktl.fi; Vesa Rasi - vesa.rasi@veripalvelu.fi; Sirkka Asikainen - sirkka.asikainen@odont.umu.se

${ }^{*}$ Corresponding author

Published: 10 December 2002

BMC Infectious Diseases 2002, 2:30
Received: 10 July 2002

Accepted: 10 December 2002

This article is available from: http://www.biomedcentral.com/ I47/-2334/2/30

(C) 2002 Mattila et al; licensee BioMed Central Ltd. This is an Open Access article: verbatim copying and redistribution of this article are permitted in all media for any purpose, provided this notice is preserved along with the article's original URL.

\begin{abstract}
Background: Periodontitis is associated with elevated levels of C-reactive protein and fibrinogen and it may be a coronary heart disease risk factor. We wanted to study if treatment of periodontitis can decrease the levels of these inflammatory markers.
\end{abstract}

Methods: C-reactive protein and fibrinogen levels were measured in 35 patients $(2 \mathrm{I} \mathrm{M,} \mathrm{I4} \mathrm{F,} \mathrm{mean}$ age 50 years) with adult periodontitis, before and after treatment.

Results: The median baseline C-reactive protein level in the patients was $1.05 \mathrm{mg} / \mathrm{l}$ and it decreased to $0.7 \mathrm{mg} / \mathrm{l}(\mathrm{p}=0.05)$ after periodontal treatment. Of the 30 patients who could be included in the analyses, 24 patients had a baseline level below $2 \mathrm{mg} / \mathrm{l}$ (the $95^{\text {th }}$ percentile limit in Finland); 6 patients had levels higher than this. Elevation of the baseline C-reactive protein level or the magnitude of its decrease were not associated with severe form of periodontitis. The decrease in C-reactive protein levels was at least $50 \%$ in $4 / 6$ of those with elevated baseline levels, as compared with $3 / 24$ of the rest of the patients $(p=0.016)$. No corresponding effect was observed in fibrinogen levels.

Conclusions: Periodontitis seems to increase C-reactive protein only in some individuals, presumably the ones reacting to it with a systemic inflammatory reaction. Periodontal treatment decreases C-reactive protein levels in these individuals and it may thus decrease their risk of coronary heart disease.

\section{Background}

Increasing body of evidence shows that $\mathrm{C}$ - Reactive Protein (CRP), measured with a sensitive assay, is an independent predictor of coronary heart disease (CHD) events. Some studies suggest that these elevated CRP lev- els reflect certain low-grade infections associated with CHD, like periodontitis and infections caused by cytomegalovirus and Chlamydia pneumoniae [1]. Some recent studies have shown that the combination of chronic infection and elevated CRP level is associated with a signifi- 
cantly higher CHD risk than either of these factors alone $[2,3]$. These observations raise the possibility that chronic infections may be CHD risk factors mostly or only in these "susceptible" individuals who react to these infections with a harmful systemic inflammatory reaction, reflected in elevated levels of CRP. Treating Helicobacter pylori and Chlamydia pneumoniae infections decreased CRP levels in the study of Torgano et al [4] but no effect was observed in the study of Schweeger et al [5].

The average CRP and fibrinogen levels are higher in periodontitis patients than in their controls [6,7]. In the study of Ebersole et al. [6] CRP levels were significantly higher ( 9 vs. $2 \mathrm{mg} / \mathrm{l}$, respectively) in 40 patients with moderate to severe adult periodontitis than in the 35 control subjects. Mechanical treatment of periodontitis did not, however, decrease CRP levels (while it did decrease haptoglobin levels).

\section{Methods}

We measured serum CRP levels before and after periodontal treatment in 35 patients with adult periodontitis. The inclusion criteria were: inflamed periodontitis indicating clinical and/or radiographic loss of periodontal attachment, the number of teeth in the dentition at least 15 , no positive history or symptoms of CHD or other significant systemic disease (e.g. diabetes or inflammatory conditions like rheumatoid arthritis), and no acute infections (e.g. common cold, sinusitis etc.) within 2 months before the entry to the study.

Periodontitis was classified as severe when alveolar bone loss was found around more than $25 \%$ of the teeth, including at least 2 teeth with bone loss over the cervical third of the root length from which more than one was a molar tooth with bone loss to the apical half of the root. Periodontal treatment comprised traditional mechanical therapy and, when indicated, metronidazole $500 \mathrm{mg}$ bid for 7 days.

CRP and fibrinogen levels were measured at baseline and 6 weeks after the completion of periodontal treatment. CRP levels were determined with a sensitive sandwich enzyme immunoassay (UC CRP ELISA, Eucardio Laboratory). With this method, $2 \mathrm{mg} / \mathrm{l}$ is the $95^{\text {th }}$ percentile limit in Finnish population, and CRP measured with this assay has been shown to predict coronary events, especially when co-occurring with certain infections [3]. Plasma fibrinogen levels were determined with Clauss method, with $3.6 \mathrm{~g} / \mathrm{l}$ being the $95^{\text {th }}$ percentile limit.

Laboratory values observed before and after the treatment were compared with paired t-test (after logarithmic conversion when necessary); Fisher' exact test or Mann-Whitney' test was used to compare the patient groups of those with baseline CRP levels above and below $2 \mathrm{mg} / \mathrm{l}$ and those with moderate and severe periodontitis, respectively.

The study protocol was approved by the ethics committee and informed consent was obtained from all participants before entering the study.

\section{Results}

Twenty-one of the patients were males and 14 females; the mean age was 50 years, with a range of 32 to 69 years. 16 subjects belonged to social class I, 9 to social class II, 10 to social class III. Seven of the patients were current smokers, 4 were ex-smokers, the rest had never smoked. None of the subjects changed their smoking habits during the study. The majority of the patients, 28 , had severe periodontitis. Nine individuals were given metronidazole. One of the subjects was excluded from the analyses due to a respiratory infection occurring immediately after the first visit. Of the rest, either the pre- or post-therapy blood sample was missing for 4 patients; thus the remaining 30 patients could be used in the analyses.

CRP and fibrinogen levels are given in Table 1. CRP levels decreased, on the average, by $0.34 \mathrm{mg} / \mathrm{l}(\mathrm{p}=0.05)$ in the whole study group. Individuals with severe periodontitis did not have higher baseline CRP levels or show a greater decrease in CRP levels. Twenty-four subjects had a baseline CRP level below $2 \mathrm{mg} / \mathrm{l} ; 6$ individuals had levels greater or equal to this value (data not shown). The decrease in CRP levels was at least $50 \%$ in $4 / 6$ of those with baseline CRP $>2 \mathrm{mg} / \mathrm{l}$ and in $3 / 24$ of those with the baseline CRP below $2 \mathrm{mg} / \mathrm{l}(\mathrm{p}=0.02)$, respectively. Only one patient treated with metronidazole showed a $50 \%$ decrease in CRP level. No significant decrease was observed in fibrinogen levels.

Table I: CRP and fibrinogen levels in the study population.

$\begin{array}{ll}\text { Baseline } & \text { Post-treatment } \\ \text { (median, range) } & \text { decrease (mean) }\end{array}$

$\begin{array}{lll}\text { Whole study group } & & \\ \text { CRP }(\mathrm{mg} / \mathrm{l}) & \mathrm{I} .05(0.2-5.4) & 0.34^{*} \\ \begin{array}{l}\text { Fibrinogen }(\mathrm{g} / \mathrm{l}) \\ \text { Severe periodontitis }(\mathrm{n}=24)\end{array} & 3.5(2.3-4.4) & 0.19 \\ \text { CRP }(\mathrm{mg} / \mathrm{l}) & \mathrm{I} .05(0.2-5.4) & 0.30 \\ \text { Fibrinogen }(\mathrm{g} / \mathrm{l}) & 3.4(2.7-4.4) & 0.05 \\ \begin{array}{l}\text { Moderate periodontitis }(\mathrm{n}=6) \\ \text { CRP }(\mathrm{mg} / \mathrm{l})\end{array} & \mathrm{I} .05(0.5-3.2) & 0.52 \\ \text { Fibrinogen }(\mathrm{g} / \mathrm{l}) & 3.7(3.2-4.2) & 0.77\end{array}$

$* p=0.05$ 


\section{Discussion}

To our knowledge this is the first study showing that treating adult periodontitis decreases CRP levels, as measured with a sensitive assay. The decrease in CRP levels observed in our study was of the same magnitude as the differences in CRP levels that have been shown to be associated with increased CHD risk in several studies [1-3] and somewhat greater than was observed after treatment of Helicobacter pylori by Torgano et al [4]. In the study by Ebersole et al [6], the patients had clearly elevated CRP levels at baseline, while the CRP levels of our patients were in the so called "normal range". The method that was used for CRP measurements in the study of Ebersole et al. may have been less sensitive in detecting changes induced by periodontal treatment.

The decrease in CRP levels occurred mostly in individuals with elevated CRP levels at baseline. Elevated baseline CRP levels or the magnitude of the decrease in the levels were not associated with the severity of periodontitis or metronidazole treatment. In contrast to CRP, fibrinogen levels did not decrease significantly. In most studies, CRP and fibrinogen have shown similar associations with CHD and various infections. Our result may be due to chance. On the other hand, the association of CRP with various indicators of poor periodontal status may be more consistent than that of fibrinogen [7] and it might therefore be more sensitive to the treatment effect.

\section{Conclusions}

As the number of patients in this study was relatively small, these results have to be interpreted with caution. Nevertheless, these results are compatible with the view that only "susceptible" individuals react to periodontitis with an increase in CRP and that these individuals are not necessarily the ones with the most severe disease. Treating periodontitis lowers CRP levels in these individuals, possibly also reducing their CHD risk.

\section{Competing Interests}

None declared.

\section{Authors' contributions}

Author 1 (K.M) participated in the planning of the study, carried out data analyses and drafted the manuscript.

Author 2 (V.V) participated in the planning of the study and writing the manuscript.

Author 3 (M.N) participated in the planning of the study and writing the manuscript.

Author 4 (S.A) participated in the planning of the study, designed the dental examinations and participated in writing the manuscript
Author 5 (M.V) participated in the planning of the study, recruited and examined the patients and participated in writing the manuscript

Author 6 (T.P) participated in the planning of the study, performed the CRP analyses and participated in writing the manuscript.

Author 7 (V.R) participated in the planning of the study, performed the fibrinogen analyses and participated in writing the manuscript.

All authors have read and approved the final manuscript.

\section{Acknowledgements}

The study was supported by the Helsinki University Hospital and by the Finnish Dental Association.

\section{References}

I. Langrand WK, Visser CA, Hermens WT, Niessen HWM, Verheugt FWA, Wolbink G-J, Hack, Hack E: C-reactive protein as a cardiovascular risk factor. more than an epiphenomenon? Circulation 1999, 100:96-102

2. Zhu J, Quyyumi AA, Norman JE, Csako G, Epstein SE: Cytomegalovirus in the pathogenesis of atherosclerosis: the role of inflammation as reflected by elevated C-reactive protein levels. JACC 1999, 34:1738-1743

3. Roivainen $M$, Viik-Kajander M, Palosuo T, Toivanen P, Leinonen $M$, Saikku P, Tenkanen L, Manninen V, Hovi T, Mänttäri M: Infections, inflammation and the risk of coronary heart disease. Circulation 2000, 101:252-257

4. Torgano G, Cosentini R, Mandelli C, et al: Treatment of Helicobacter pylori and Chlamydia pneumoniae infections decreases fibrinogen plasma level in patients with ischaemic heart disease. Circulation 1999, 99:1555-1559

5. Schweeger I, Fitscha P, Sinzinger H: Successful eradication of Helicobacter pylori as determined by $((13))$ C-urea breath test does not alter fibrinogen and acute phase response markers. Thromb Res 2000, 97:4 I I-420

6. Ebersole JL, Machen RL, Steffen MJ, Willmann DE: Systemic acutephase reactanta, C-reactive protein and haptoglobin, in adult periodontitis. Clin Exp Immunol 1997, 107:347-352

7. Wu T, Trevisan M, Genco R, Falkner K, Dorn J, Sempos C: Examination of the relation between periodontal health status and cardiovascular risk factors: serum total and high density lipoprotein cholesterol, C-reactive protein and plasma fibrinogen. Am J Epid 2000, I 5 I:273-282

\section{Pre-publication history}

The pre-publication history for this paper can be accessed here:

http://www.biomedcentral.com/1471-2334/2/30/prepub 